\title{
BEYOND SOCIAL SKILLS: GROUP DYNAMICS AT SOCIAL SKILLS TRAINING FOR HIGH FUNCTIONING ADOLESCENTS WITH AUTISM SPECTRUM DISORDERS
}

\author{
Agnieszka Siedler \\ University of Social Sciences and Humanities, Warsaw, Poland \\ Autism Diagnosis and Therapy Center "Navicula", Łódź, Poland \\ E-mail: a.siedler@gmail.com
}

\begin{abstract}
The usefulness of group social skills training in Autism Spectrum Disorder therapy has been well established. However, little is known about the group dynamics of this kind of intervention. The current multiple case studies were conducted to demonstrate that, despite of the functioning specifics of participants with $A S D$, processes associated with the dynamics of the group during group social skills training session may be noticeable. Intervention groups consisted of fifteen adolescents and preadolescents with high functioning Autism Spectrum Disorders aged between 11 to 17 years old divided into three training groups. The social skills training sessions were conducted on a weekly basis. The observation lasted for six months and it included the formation of the group, the period of stability and unexpected changes. After each group session, the therapists filled in a detailed report about the participants' behavior and interactions between participants. Collected data were carefully analyzed for group dynamic features. It was noticed that adolescents participating in group interventions are susceptible to the influence of the group, take different individual roles and are moderately sensitive to changes in the group structure. The influence of the disorder characteristics on group dynamics was also observed. Although the results show that group dynamics can be observed at a group training for ASD, the need for further structured observation should be emphasized as a current study constituted the first approach to the subject.

Preliminary study: Benefits and challenges for participants beyond social skills obtaining are discussed. Key words: autism, Asperger Syndrome, group intervention, social skills training, groups' roles, group dynamics.
\end{abstract}

\section{Introduction}

There are many different types of therapies for people with Autism Spectrum Disorders. Most of them are intended for toddlers and younger school-age children. The therapeutic offer for adolescents is not so wide, however, individuals still need diverse types of support. One of the most popular interventions for adolescents are social skills training groups.

Social skills training sessions for children and adolescents with Autism Spectrum Disorders (ASD) are usually the kind of group interventions (Andanson, Pourre, Maffre \& Raynaud, 2011; Marriage, Gordon \& Brand, 1995; Castorina \& Negri, 2010; Barry, Klinger, Lee, Palardy, Gilmore \& Bodin, 2003). 
The main characteristics of ASD are social skills impairment, lack of behavioral and think-

ing flexibility and restricted interests (Atwood, 2006; Frith, 2008), but they also lack of empathy, have a poor non-verbal communication and bizarre way of speaking (Wing, 1986). Asperger Syndrome does not affect intelligence, but individuals are frequently perceived as less intelligent in certain social situations (Vermeulen, 2001). Research taken in the field of social skills training shows its impact on social skill improvement, but suggests poor generalization to non-clinic setting (Barry, Klinger, Lee, Palardy, Gilmore \& Bodin, 2003; Castorina \& Negri, 2010). Training that uses narrative techniques has an influence on failure-related and decision-related component of action-control (Waligórska, Siedler \& Waligórski, 2010). Unfortunately, there is no research focusing on processes during the social skills group training sessions, that are not related with training objectives. Trainings are perceived as an in-group learning of social skills, omitting possible therapeutic aspect of group intervention.

The group is being commonly defined as: two or more people who interact with one another, share similar characteristics and goals, define their own standards, create group structure and collectively have a sense of unity (Mika, 1981). Group training as a particular kind of group also manifests most of the social group features. Furthermore, that type of intervention can also have few characteristics of group therapy. According to Yalom (Yalom \& Leszcz, 2006), group therapy helps individuals through eleven basic factors: hope, feeling that "I'm not alone", sharing information, altruism, corrective recapitulation of the first family group, development of socializing techniques, behavior imitation, interpersonal learning, group consistency, catharsis and existential factors. Group therapy for adolescents with Asperger's Syndrome improves the ability to develop and maintain relationships with others (Longhurst, Richards, Copenhaver \& Morrow, 2010).

Individuals engage in group interaction for many reasons. One of them is socialization and the need to feel a sense of belonging, that is one of the most basic needs for an individual (Maslow, 1954). It predicts better physical health (Hale, Hannum \& Espelage, 2005) and quality of life (Jones, 2003). Sense of belonging also determines healthy child development (Filipczuk, 1980). Motivating to engage in social relationships is one of the essential components of one's well-being (Cacioppo et al., 2007). Children and adolescents with High Functioning Autism (HFA) and Asperger's Syndrome (AS) also have the need of belongingness (Pisula, 2003), but for them it is much more difficult to fulfill (Laursen \& Yazdgerdi, 2012). But social interactions of people with ASD are believed to be shallow as individuals are not able to accurately empathize with another person.

As a basis for the current study it was assumed, that beyond learning social skills that type of group intervention may have also a therapeutic dimension, typical for other types of group treatment. The purpose of this study was to observe what kind of group dynamics, group roles and healing factors can be observed during the group interventions for adolescents with ASD.

\section{Methodology of Research}

The study was performed at Autism Diagnosis and Therapy Center in Łódź, Poland, an institution with over 1000 individuals with Autism Spectrum Disorders under stationary or ambulatory care. Due to the lack of detailed preliminary research, the exploratory case study design was used. Three groups, differing in age range, were taken into account.

\section{Participants}

The sample consisted of fifteen children, ranging from 11 to 17 years old, all males. They were divided into three groups: 11 to 12 years old; 13 to 15 years old and 15 to 17 years old. Participants had a diagnosis confirmed by a psychologist and psychiatrist. Six of the participants had a diagnosis of High Functioning Autism and nine participants had a diagnosis of Asperger's Syndrome.

\section{Procedure}

The social skills training group sessions were conducted on a weekly basis for six months, from September 2013 to March 2014. Every session was conducted by two psychologists with 
multiple years of experience in ASD therapy and social skills training. Psychologists were assigned to a certain group. The participants were recruited and assigned to the social skills training groups, based on age and functioning level. After each session one of the psychologists created a detailed report about each of the participants' behavior and interactions with other participants for further analysis. Psychologists used methods like role playing, informing, discussion, modeling, shaping, social stories, behavior rehearsal, getting feedback, dyad exercises, games and coaching. The main purpose of each session was to develop social skills. The participants were learning about the social context of emotions, social perception, self-regulation, self-monitoring, social rules and training basic social skills (like maintaining eye contact, respecting personal space, gestures) and complex social-skills (like conflict resolution, dealing with teasing and dating). The content of the training was adapted to the needs of a particular training group.

\section{Analyses}

Collected data were analyzed for the presence in the description of the behavior of the participants and their interaction characteristics of group dynamics and healing factors. Two independent judges, both psychologists, evaluated reports from social skills group session. The following components were assessed:

- Healing factors: hope, feeling that "I'm not alone", sharing information, altruism, corrective recapitulation of the first family group, development of socializing techniques, behavior imitation, interpersonal learning, group consistency, catharsis and existential factors.

- Group roles: leader, observer, aggressor, disrupter, clown, scapegoat, yes-man, outsider, toady and group conscience.

- Stages of group development: forming, storming, norming and performing.

- Characteristics of group dynamics, like: unspoken rules and norms, group coherence, intermember relations, features of group identity, values, communication patterns, conflicts and problem solving, spontaneous cooperation.

\section{Observation Results}

\section{Group 1}

The group consisted of five boys aged 11 to 12 years old. At the first session group members agreed to the rules of behavior and mutual interactions at the group meetings and the objective of the participation in social skills training. Boys were very agreeable and silent. Formal leader was encouraging them to talk. They quickly realized that they had similar interest. Participants seemed to be dazed by being in group interactions for the next 5 weeks. Three boys insistently tried to get the attention of others, by clowning, speaking very loudly and showing-off. Two boys stayed quiet and observed the group. They started to share their interest with each other a lot and getting into the dialog. The psychologist, besides carrying on social skills exercises, tried to support them in creating correct interactions and include all the participants in the discussion. One boy at the beginning of the program was frustrating because of others inappropriate behavior, he showed low resistance. Behaviors like rushing out of class, hiding under the chair and reversing his chair were observed. After 8 weeks of sessions the group has created unspoken rule - not to upset this boy. Despite the fact that the boys still like to make jokes they tried to monitor his reaction and stopped before his tension level reached the breaking point. The group reached a stable point and for the next weeks worked very effectively. Participants knew each other and felt safely. Parents reported that boys didn't like social skills training exercises, but they liked coming to the session because of their contact with friends. This tendency was stronger for the boys with Asperger's Syndrome that with autism. About $12^{\text {th }}$ week the psychologist started to observe creating of the alliance. Two boys were always sitting next to each other, talking a lot. The psychologist even suggested them to exchange their phone numbers, but it was a hard task for them. It took next four weeks until 
they finally did it. At $20^{\text {th }}$ week three participants with Asperger's Syndrome started asking ques-

tions about why they need to learn those things about emotions and social interactions while they don't need them. They also felt that two other boys (absent that day) were different from them. They tried to confront together with the group formal leaders. Differences and similarities in the group were discussed and the participants agreed with jointly established conclusion: "They are a little bit different from them, but we are also similar. Together we have similar difficulties and the practice may help us". The aspect of "not being alone" seemed to be important for boys as well as the possibility of sharing information with each other. At the time when the observation ended there was no informal leader in the group and no specific group roles.

\section{Group 2}

The group consisted of five boys aged 13 to 15 years old. At the first session group members agreed to group rules and goals. Four of them had a diagnosis of High Functioning Autism and one had a diagnosis of Asperger's Syndrome. For the first four weeks one of the participants tried to get other's attention by giving early Christmas gifts and telling riddles. Such behavior did not disappear till the end of the observation. The boy also started to bring his toy figures with him to show it to other group members. Intensive approval seeking was observed. On the other hand, the boy started to build the wall between him and the rest of the group by bringing books with him to the sessions. He wouldn't come into the classroom without the book and he had to have it near him. Usually, after he talked about his experience and after he shared with others his interests he started to read. He kept reading until someone asked him a direct question or until the group started to play a game. Psychologists named his role in the group as an outsider. Changing his habit was a long process that did not end completely until the end of the observation. What was achieved, the boy started to put his book aside more often.

After four weeks group roles could be observed. The group had an informal leader, who was making all decisions in a group, was very active in discussions, and was asking questions other members of the group and including the formal leaders. Two other participants manifested a conformist attitude. They never asked the question spontaneously and were passive in discussions. One last participant unfortunately was a scapegoat. Communicating with others was a little bit harder for him than for the rest of the group. The group has not commented on their own mistakes, however, made fun from a scapegoat. The psychologist had to put a lot of effort to change the boys' group role. After they succeeded the group reached the point of stable structure and could work effectively.

\section{Group 3}

The group consisted of five boys aged 15 to 17 years old. At the first session group members agreed to group rules and goals. All five of them had a diagnosis of Asperger's Syndrome. The participants tried to get each other's attention for twelve weeks. They were also intensively testing the boundaries set by psychologists. The following behaviors have been observed: inappropriate language, raising difficult subjects, shouts, loud singing, attempt to hit the colleague, attempt to hit the psychologist. In a very short period of time two opposing alliances were created. Two of the participants competed for the position of informal group leader, each one had one friend on his side. The fifth boy adopted the role of the oppositionist - he never agreed with anything said on the group, he did not like the proposed activities and he did not opt on anyone's side. This structure was visible even in the way of chairs set up. Because of the conflict, it was difficult for the group to focus on the exercises. The psychologist made an attempt to talk about it. Unfortunately, it was very difficult for the participants to realize their emotions in relation to the group. The conflict escalated to the moment one of the participants resigned. The boy's parents were not able to convince him to come back. As a reason, he stated that the sessions did not meet his needs.

After one aspiring leader left the group, the one left could take the role. The group life calmed down and could focus on social skills. The participants in that group willingly shared information and helped each other. They started to solve their problems from outside the group by discussing 
them with other group members. On the $16^{\text {th }}$ week one of the participants said that he liked to come to the sessions because of the group as a whole, because he liked to be in that group.

\section{Discussion}

The results of the observation were consisted with the assumptions. In all the groups features of group dynamics and healing factors could be observed. Some of the participants received group roles. The groups passed through various phases of group development. Healing factors like feeling that "I'm not alone", sharing information and behavior imitation were also observed. It confirms the thesis of the group dynamics existence in social skills training groups. That kind of intervention may be compared to group therapy. Previous studies focused mostly of differences between social skills training groups and group psychotherapy (Lehtsaar, 1987), but did not include observations of a group as specific as adolescents with Autism Spectrum Disorders. Despite the difficulties associated with a disorder, features typical for other group interventions could be observed.

It could be noticed, that less rated aspects occurred in the youngest group, aged 11 to 12 years old. Possibly, younger adolescents are not able to engage in social interactions as much as older adolescents. From the therapeutic perspective, for this age range probably it is probably better to focus on behavioral interventions at group trainings than including group dynamic influence. Older children, aged 13 to 15 years old and aged 15 to 17 years old were benefited not only from structured exercises, but also from "being" in the group.

\section{Conclusion}

In this research it was shown, that in social skills training sessions, group dynamics can also be observed. For people with High Functioning Autism and Asperger's Syndrome that may be another factor that helps them. Besides teaching social skills, the participants can also receive social support, find an accepting peer group and work on their self-identity. Since presented study was only a preliminary observation of a group process of this kind of intervention, there is a need to conduct further research, including structured observation.

\section{References}

Andanson, J., Pourre, F., Maffre, T., Raynaud, J. P. (2001). Social skills training groups for children and adolescents with Asperger syndrome: A review. Archives de Pediatrie, 18 (5), 589-596.

Attwood, T. (2006). Zespót Aspergera [Asperger’s Syndrome]. Poznań: Zysk i s-ka Publishing.

Barry, T. D., Klinger, L. G., Lee, J. M., Palardy, N., Gilmore, T., Bodin, S. D. (2003). Examining the effectiveness of an outpatient clinic-based social skills group for high-functioning children with autism. Journal of Autism \& Developmental Disorders, 33 (6), 685-701.

Cacioppo, J. T., Amaral, D. G., Blanchard, J. J., Cameron, J. L., Carter, C., Crews, D., Quinn, K. J. (2007). Social neuroscience: Progress and implications for mental health. Perspectives on Psychological Science, 2, 99-123.

Castorina, L. L., Negri, L. M. (2010). The inclusion of siblings in social skills training groups for boys with asperger syndrome. Journal of Autism and Developmental Disorders, 41 (1).

Filipczuk, H. (1980). Potrzeby psychiczne dzieci i mlodzieży [Psychological needs of children and adolescents]. Warsaw: Publishing Institute CRZZ.

Frith, U. (2008). Autyzm: Wyjaśnienie tajemnicy [Autism: Explaining the enigma]. Gdańsk: Gdańsk Psychological Publisher GWP.

Hale, C., Hannum, J., Espelage, D. (2005). Social support and physical health: The importance of belonging. Journal of American College Health, 53 (6), 276-284.

Jones, R. C. (2003). Sense of belonging and its relationship with quality of life and symptom distress among undergraduate college students. Proquest, Umi Dissertation Publishing. 
Lehtsaar, T. (1987). Using psychotherapeutic methods in social skills training. Soviet Psychology, 25 (3), 83-91.

Longhurst, J., Richards, D., Copenhaver, J., Morrow, D. (2010). "Outside In" group treatment of youth with Asperger's. Reclaiming Children \& Yout, 19 (3), 40-44.

Marriage, K. J., Gordon, V., Brand, L. (1995). A social skills group for boys with Asperger's syndrome. Australian and New Zealand Journal of Psychiatry, 29 (1), 58-62.

Maslow, A. (1954/1990). Motywacja i osobowość [Motivation and personality]. Warsaw: Publishing Institute PAX.

Mika, S. (1981). Psychologia spoteczna [Social psychology]. Warsaw: P.W.N. Publishing.

Pisula, E. (2003). Autyzm i przywiqzanie [Autism and attachement]. Grańsk: Gdańskie Wydawnictwo Psychologiczne.

Waligórska, A., Siedler, A., Waligórski, M. (2011). Narracje osób z Zespołem Aspergera z perspektywy terapeutycznej [Narrations of individuals with Aspergers Syndrome from therapeutic perspective]. In: Dryll, E., Cierpka, A. (Eds.) Psychologia narracyjna [Narrative psychology]. Warsaw: Eneteia Publishing.

Wing, L. (1986). Asperger syndrome: A clinical account. Psychological Medicine, 11, 115-129.

Vermeulen, P. (2001). I am special. London and Philadelphia: Jessica Kingsley Publisher.

Advised by Vincentas Lamanauskas, Siauliai University, Lithuania

Received: March 09, 2015

Accepted: June 10, 2015 